UDC 001.9

LBC 60.0

\title{
SCIENTIFIC AND EDUCATIONAL PRACTICES IN TERMS OF INFORMATION TECHNOLOGIZATION OF INTELLECTUAL ENVIRONMENT
}

\author{
Svetlana B. Tokareva \\ Volgograd State University, Volgograd, Russian Federation \\ Tatyana S. Gorina \\ Volgograd State University, Volgograd, Russian Federation
}

\begin{abstract}
Absract. The article presents scientific enlightenment as a kind of social practice the initial forms of which has appeared in modern times and are reflected in the rhetoric and social rituals confirmed in the public consciousness, the recognition of the intellectual superiority of science and the unavailability of its profane consciousness. The research paper shows the place of scientific enlightenment in the philosophical project of the Enlightenment related to its role in enhancing the literacy of different social groups, the emancipation of ordinary consciousness, the increasing authority of science. The paternalistic model of scientific enlightenment based on the idea of cognitive deficit and approving the regulation of the content and forms of "popular science" by academic institutions is described.

The specificity of modern "popular science" due to its localization in extraacademic media space is shown. The change of social requests for scientific enlightenment is focused not so much on the problem of eliminating the deficit of scientific and functional literacy but on the integration of the popularization of science with the sphere of leisure. The goal is not to become familiar with the achievements of science but to increase the diversity of leisure that makes scientific enlightenment a part of the entertainment business.

Psychological obstacles to the development of scientific education due to the specific communicative environment of the Internet are revealed. Consumer orientation to a small volume of messages, visualization and a high level of interactivity reduces the demand for educational and scientific-educational information resources characterized by a low level of interactivity offer rich content of voluminous texts, require skills of interpretation, analytical synthesis, basic scientific culture. The information transmitted by such resources often causes psychological discomfort to the consumer and is rejected as excessive.

The transition to the present stage of institutionalization of scientific education in the conditions of informatization of the intellectual environment is analyzed. The main tendencies of a new stage in the institutionalization of scientific enlightenment are pointed out: the rejection of a paternalistic model of interaction with various social groups; the idea of equal dialogue between science, government and society; the desire to involve non-experts in academic activities.
\end{abstract}

Key words: scientific enlightenment, scientific and educational practice, science, popular science, informatization, information technologization.

\section{НАУЧНО-ПРОСВЕТИТЕЛЬСКИЕ ПРАКТИКИ В УСЛОВИЯХ ИНФОРМАЦИОННОЙ ТЕХНОЛОГИЗАЦИИ ИНТЕЛЛЕКТУАЛЬНОЙ СРЕДЫ}

\author{
Светлана Борисовна Токарева
}

Волгоградский государственный университет, г. Волгоград, Российская Федерация 


\section{Татьяна Сергеевна Горина}

Волгоградский государственный университет, г. Волгоград, Российская Федерация

Аннотация. В статье научное просветительство представлено как вид социальной практики, первоначальные формы которой сложились в Новое время и нашли отражение в риторике и социальных ритуалах, утвердивших в общественном сознании признание интеллектуального превосходства науки и недоступность ее профанному сознанию. Показано место научного просветительства в мировоззренческом проекте Просвещения, обусловленное возлагаемой на него миссией повышения грамотности различных социальных групп, эмансипации обыденного сознания, повышения авторитета науки. Описана патерналистская модель научного просветительства, базирующаяся на идее когнитивного дефицита и утверждающая необходимость регламентации содержания и форм «популярной науки» со стороны академических институций.

Показана специфика современной «популярной науки», обусловленная ее локализацией во внеакадемическом медиапространстве. Выявлено изменение социальных запросов на научное просветительство, ориентированных не столько на задачу преодоления дефицита научной и функциональной грамотности, сколько на сращивание популярной науки со сферой досуга с целью увеличения его разнообразия. В результате научное просветительство превращается в часть развлекательного бизнеса.

Выделены психологические препятствия развития научного просветительства, обусловленные спецификой коммуникативной среды Интернета. Ориентация потребителя на небольшой объем сообщений, визуализацию и высокий уровень интерактивности снижает спрос на те образовательные и научно-просветительские информационные ресурсы, которые отличаются низким уровнем интерактивности, предлагают насыщенные содержанием объемные тексты, требуют навыков интерпретации, аналитического обобщения, базовой научной культуры. Транслируемая такими ресурсами информация часто вызывает у потребителя психологический дискомфорт и отвергается как избыточная.

Проанализирован переход к современному этапу институализации научного просветительства в условиях информационной технологизации интеллектуальной среды. Выделены основные тенденции нового этапа институционализации научно-просветительских практик: отказ от патерналистской модели взаимодействия ученых с различными социальными группами; идея равноправного диалога науки, власти и общества; стремление к вовлечению неспециалистов в научную деятельность.

Ключевые слова: научное просветительство, научно-просветительская практика, наука, популярная наука, информатизация, информационная технологизация.

Основы взаимодействия ученых с властью и обществом сложились в период Нового времени одновременно с формированием науки и научного сообщества. Они нашли отражение в социальных ритуалах и риторике, отражающих признание интеллектуального превосходства науки, ее относительную автономность и закрытость научного сообщества как профессиональной группы, а также недоступность научного знания широкой публике в силу отсутствия у носителей профанного сознания необходимой подготовки. Получившие в этот период распространение формы популяризации науки - публичные лекции, демонстрации научных опытов - были нацелены прежде всего на привлечение меценатов и поиск покровительства элит. Позднее, в эпоху Просвещения, идеологи которой видели в распространении науки и грамотности единственный надежный путь к расцвету цивилизации, стремление сделать научные знания привлекательными и доступными для широких масс привело к тому, что функция «неограниченного распространения обучения, направляемого исследованиями», окончательно и бесповоротно закрепилась за университетами [13].

Мировоззренческий проект Просвещения утвердил популяризацию научных идей в качестве приоритетного пути эмансипации общественного сознания. Он был направлен на укрепление связи науки, общества и средств массовой коммуникации. Это нашло свое отражение в развитии научно-популярных журналов, научной фантастики, научнопопулярных фильмов, а позднее привело к появлению высококачественной индустрии популяризации науки, блестящими образцами которой являются телевизионные программы ВВС [1, с. 47-50].

Главная задача, на решение которой были направлены проекты популяризации науки, устранение дефицита «научной грамотности». Для этого популярная наука должна была стать частью дополнительного образования, в рам- 
ках которого ей следовало излагаться адекватно пониманию ее авторитетными представителями научного сообщества. Считалось, что только такое изложение научных достижений гарантирует «дальнейший рост интереса к науке и технологическим инновациям со стороны обывателей» [1, с. 52]. При этом контроль за содержанием и адекватностью изложения научной информации возлагался на научное сообщество, тогда как интересы и потребности общественности не слишком принимались во внимание. В результате стремление популяризировать прежде всего фундаментальное знание сталкивалось с непреодолимыми препятствиями - незнанием научной терминологии, недостаточным уровнем базовой подготовки.

В информационном обществе популяризация науки становится ответом на вызовы экономики знания. Под влиянием «технических мутаций» [11] происходит трансформация коммуникационной культуры, радикально изменяются сферы производства и управления. Недостаток образованных научных и технологических кадров несет угрозу замедления экономического прогресса, поэтому на рынке труда «решающую роль начинает играть интеллектуальный кадровый капитал, рынок квалифицированных человеческих ресурсов, профессионалов, чей потенциал и система профессиональных и личностных ценностей соответствуют новой информационно-коммуникационной среде» [10, с. 134-135].

Однако по мере информационной технологизации популяризация науки также все более становится средством разнообразия сферы досуга и фактически срастается с ней, используя безграничные возможности Интернета. Этот бросающийся в глаза рост «общественного интереса» к науке при более пристальном рассмотрении оказывается симуляцией: в действительности популяризация науки имеет целью не приращение знания через приобщение к достижениям науки, а увеличение разнообразия досуга. Научное просветительство становится частью развлекательного бизнеса [2, с. 54]. Медийная составляющая становится не менее важной, чем научная, в связи с чем возникает спрос на «“хипстерскую науку”, интегрированную в программные платформы для смартфонов и “нарезанную” небольшими порциями в формате увлекательных видеороликов» [1, с. 47].

Сращивание популяризации науки со сферой досуга и потребность в адаптации к жизни в интеллектуальной среде изменили вектор социального запроса на популяризацию научных знаний: он исходит уже в большей степени не от ученых, а формируется в массах по мере осознания дефицита научного знания. И хотя отказа от двухфазной модели популяризации науки не произошло - по-прежнему считается, что знание сначала создается наукой, а затем передается в облегченной форме заинтересованной публике $[1$, с. 56], выбор этого содержания уже не определяется целиком и полностью научным сообществом, но ориентируется на интересы «заказчика».

В условиях демократического и технократического общества возрастает необходимость осведомленности населения о научных разработках для принятия рациональных решений, касающихся их использования и влияния на различные аспекты жизни. Сама общественная жизнь перемещается в информационно-сетевую среду [4; 6; 12; 14], к которой люди должны адаптироваться: во-первых, в технологическом отношении - знать устройство новых технологий и иметь представления о науке, которая за ними стоит; во-вторых, в социально-политическом отношении иметь критическое мышление, позволяющее ориентироваться в потоках информации и уметь принимать «взвешенные демократические решения относительно научной сферы» $[1$, с. 50].

Новые задачи порождают новые модели взаимодействия общества и науки, а также новые социальные практики, связанные с вовлечением в научную деятельность неспециалистов и стремлением привлечь научное сообщество к решению насущных проблем, обеспечить если не равноправный диалог науки и общества, то реальное участие широких масс в процессах производства и трансляции научного знания. Препятствиями на пути достижения этой цели являются, с одной стороны, неготовность научного сообщества к критике и социальному контролю развития науки со стороны общества, а с другой - существующая внутри академической науки система разделения интеллектуального труда, 
которая не предусматривает участия в научных спорах представителей различных социальных групп. Поэтому чаще всего «процесс вовлечения публики (public engagement) является не более чем риторикой и манифестацией намерений» $[1$, с. 56]. Наука продолжает отстаивать свою академическую автономию на производство и верификацию научного знания, однако как только научное знание выходит в «ничейное» пространство на стыке науки, медиа и публики, когнитивный статус ученых меняется. Их основной функцией становятся упрощение материала и представление его широкой публике.

В этой связи появляется необходимость институционализации научного просветительства. Если социальные практики естественным образом «вызревают» в жизнедеятельности общества, то их институционализация позволяет перевести процесс в контролируемую стадию, поскольку социальный институт регламентирует деятельность и связанные с ней социальные роли и статусы, средства и методы. Институционализация научного просветительства предполагает формирование норм, ценностей, образцов поведения и набора социальных ролей в этой сфере деятельности. Современный этап институционализации научного просветительства проходит в условиях информационной технологизации интеллектуальной среды и характеризуется отказом от патерналистской модели отношений научного сообщества и масс, утратой академическими институциями и научным сообществом контроля над содержанием транслируемого знания. Изменяется и содержание понятия «популярная наука»: оно, во-первых, указывает на новую локализацию научного знания «вне контролирующих его значение условий лаборатории или научной среды» [1, c. 48] - в пространстве взаимодействия науки, медиа и общественного сознания; во-вторых, отражает расширение круга научно-популярных явлений, включающих «и представления обычных людей о науке, и их поведение как способ употребления и актуализации научного знания, и особую систему коммуникации научного сообщества, медиа и общества» [1, с. 48].

Представляется, что развитие популярной науки будет идти в направлении дифференциации моделей коммуникации. Например, в области современных биосоциальных технологий, где исследования создают нестандартные и весьма острые морально-этические, психологические и правовые проблемные ситуации, возникает необходимость решения этих проблем с участием специалистов из различных сфер знания и широкой общественности. Для фундаментальных наук сохраняется актуальность формы «занимательной науки» по причине неустранимого когнитивного дефицита. Социально-гуманитарные науки, с одной стороны, нуждаются в современных формах популяризации и пропагандирования знаний о человеке и обществе для борьбы с социальными мифами (прежде всего в области истории и политических наук). С другой стороны, в этих областях научное знание все чаще выступает в роли экспертного знания, в котором продуктивно использование вненаучных форм знания и повседневного опыта, что создает предпосылки для полноценного участия широкой общественности и институтов гражданского общества в научной экспертизе.

Интеллектуальный хабитус эпохи модерна сформировался под решающим влиянием науки. Его можно определить как систему «умственных привычек» людей связывать практическую логику, успешное действие и продуктивную стратегию поведения с исследованием, объяснением, прогнозированием и преобразованием реальности, а также как привычку видеть в научном просветительстве исключительно средство эмансипации сознания.

Появившаяся возможность использовать Интернет как средство прямого обращения к широкой аудитории или размещения научных материалов на сайтах научных учреждений не только создает «эффект получения знания “из первых рук”, но и является мощным стимулом для привлечения в науку молодежи» [3, с. 92]. В связи с этим формируются новые социальные практики научного просветительства, которые постепенно становятся частью нашего мира опривыченных действий. Их опыт объективируется в наборах когнитивных, этических, лингвистических диспозиций, задающих мыслительные и поведенческие схемы для практики взаимодействия ученых с властью, обществом и средствами массовой коммуникации; практики рекрутирования молодежи в систему 
образования с дальнейшими перспективами занятий наукой; практики критического мышления; практики противодействия общественного сознания лженаучным знаниям и различным проявлениям псевдонаучности.

Стремительно набирающее популярность благодаря использованию Интернета научное просветительство сталкивается с препятствиями, обусловленными спецификой современного коммуникативного паттерна. Коммуникативная среда Интернета характеризуется высоким уровнем «информационного шума», порожденного избыточностью информации [9]. В этих условиях включаются психологические фильтры (дефлекторы) [8], маркирующие определенные виды информации как «шумовые» и снижающие интенсивность входящего потока сообщений за счет их отклонения. При этом критерии отбора не связаны с прагматической ценностью и релевантностью информации; в качестве «шумовой» отклоняется информация, вызывающая психологический дискомфорт в силу ее несоответствия типу коммуникации, сложившемуся при взаимодействии с онлайновыми Интернет-ресурсами: небольшой объем сообщений, визуализация, высокий уровень интерактивности и т. п. Однако для образовательных и научно-просветительских информационных ресурсов характерны как раз эти черты: они отличаются низким уровнем интерактивности, предлагают насыщенные содержанием объемные тексты, которые обладают формальным или понятийным аппаратом и требуют навыков интерпретации, аналитического обобщения, предполагают наличие базовой научной культуры. Все это вызывает у потребителя психологический дискомфорт, так что действующие дефлекторы формируют в отношении транслируемой этими ресурсами информации негативные психологические установки и создают препятствия для ее освоения.

Готовность к восприятию научной информации обеспечивается за счет когнитивных ресурсов. За длительное время существования науки в качестве относительно автономного социального института и особой формы познания сложился хабитус науки - устойчивый элемент когнитивной структуры, рутинизирующий выработанные научным сообще- ством исследовательские навыки и способы трансляции знания. Описание реальности путем группировки фактов в свете усвоенных идеальных моделей является типичным проявлением такой хабитуализации. В условиях сформировавшегося хабитуса науки ее ценности - истина, научное объяснение, теория, научный закон - выступают в качестве артикулируемых объектов интенции познавательных действий человека, что позволяет интерпретировать познавательное поведение ученого телеологически, связывать его с целью и намерением. В обществе, признающем высокий статус науки, такая поведенческая модель экстраполируется и на систему образования, включая научное просветительство как его элемент: считается, что обучающиеся и интересующиеся наукой люди имеют схожий с учеными познавательный интерес. Разница лишь в том, что они приобщаются к готовому знанию, а не добывают его самостоятельно в процессе исследования, а потому усвоение элементов научного знания в ходе образовательного процесса и приобщение к достижениям науки в рамках научного просветительства требует мыслительных операций и когнитивных навыков, соответствующих хабитусу науки.

Однако информационно-коммуникативная среда не способствует поддержанию этих интеллектуальных навыков. В информационной среде когнитивная структура перестраивается: хабитусы научной и образовательной деятельности трансформируются под влиянием новых, рутинизирующих работу с информационными потоками. В результате увеличивается когнитивный разрыв науки и образования: научный хабитус, облегчающий интеллектуальные действия, связанные с исследовательской деятельностью и трансляцией научного знания, становится все более специализированным. В этих условиях научное просветительство также нуждается в собственном специализированном хабитусе, обеспечивающем автоматизацию мыслительных операций и интеллектуальных навыков, необходимых для усвоения достижений современной науки в условиях информационной среды.

Под влиянием разработанной А. Шюцем феноменологии социального мира в социальные науки прочно вошло убеждение о важ- 
ности когнитивных схем для рутинизации, «опривычивания» социальных практик. Конституирующим элементом конкретной социальной практики как относительно обособленной «области конечных значений» в пределах жизненного мира является ее когнитивный стиль (или когнитивная структура знаний), изучение которого требует привлечения философской методологии и выходит за рамки конкретно-научного знания. Так, представитель микросоциологического подхода Б. Латур считает, что социология знания вполне может оставить за рамками рассмотрения когнитивные структуры и сосредоточиться на повседневных практиках, в которых знание конструируется, поскольку причиной рутинизации социальной практики является повторение однотипных событий. Согласно этой позиции, «отдельные случаи, повторяясь, приобретают цикличный, привычный характер, становятся рутинными и наделяются символическим значением» [5, с. 115].

Однако более глубокое изучение проблемы требует различать социальное конструирование знаний на базе когнитивных схем, с одной стороны, и процесс хабитуализации социальных практик, в ходе которого формируются и изменяются сами когнитивные (ментальные) структуры, - с другой. Именно благодаря социальным хабитусам - общим схемам интерпретации - события начинают восприниматься как однотипные. Таким образом, когнитивный подход выступает альтернативой микросоциологическому подходу в социальном познании и стремится объяснить социальное поведение сложившимися ментальными образованиями - системами образов, понятий, схемами категоризации. Благодаря им впечатления индивидов об окружающем мире организуются в связные интерпретации, на основе которых образуются идеи, убеждения, установки и т. п., выступающие регуляторами социального поведения. Для научной деятельности и просветительства значимыми (хотя и в разной степени) являются следующие когнитивные схемы: категоризации, обеспечивающие избирательное отнесение восприятий к той или другой категории; схемы процессов дифференциации смыслов и артикуляции отдельных идей; схемы процессов центрации - соотнесения объектов восприятия (переживания) с центральной (ассимилирующей) идеей или признаком, благодаря чему возникает синергия мыслительных процессов, уменьшаются избыточные степени свободы мышления и преодолевается разбросанность мысли. Более поздние когнитивные структуры выполняют сложные функции управляющих центров, проводных путей и каналов коррекции мыслительной деятельности. Таким образом, когнитивные техники «канализируют» мыслительную практику, обеспечивая тематизацию мышления. Однако если для науки образование все более сложных конфигураций мысли за счет остановки других реакций образности, воображения - является стандартной процедурой, то в научно-просветительских практиках «онагляживание» является важнейшим условием понимания и зачастую играет определяющую роль.

Для понимания механизма формирования габитусов научной деятельности и научного просветительства важна идея А. Шюца о том, что познавательные практики предполагают иной горизонт релевантности по сравнению с практическими действиями. Особенность практических действий состоит в том, что они являются предметными, направленными на преобразование действительности, ее сложное изменение. Движениями в них управляют смысловые образы. Смысловой характер структуры этих движений «раскрывается как целесообразность, намеренность, проективность» [7, с. 171]. Предметные действия начинаются с предвосхищения результата, который не всегда выступает результатом познания, хотя такое предвосхищение иногда отождествляют с познавательным образом как продуктом мышления, однако интенция «привычно предвосхитить результат» отличается от интенции «знать» [7].

Проведенный анализ показывает, что на современном этапе институционализации научно-просветительских практик, проходящем в условиях информационной технологизации, на формирование готовности представителей различных возрастных и социальных групп к восприятию научной информации оказывает влияние широкий спектр социальных, исторических, психологических и когнитивных условий, задающих ключевые характеристики интеллектуальной среды и определяющих ее изменения. Дальнейшее изучение влияния этих 
трансформаций на исследовательские и образовательные практики является необходимым условием повышения эффективности научного просветительства.

\section{СПИСОК ЛИТЕРАТУРЫ}

1. Абрамов, Р. Н. Концептуализация феномена Popular Science: модели взаимодействия науки, общества и медиа / Р. Н. Абрамов, А. А. Кожанов // Социология науки и технологий. - 2015. - Т. 6, № 2. - С. 45-59.

2. Ваганов, А. Г. Ученые и журналисты: проблемы коммуникации / А. Г. Ваганов // Наука. Инновации. Образование. - 2016. - №2. - С. 48-60.

3. Горбунов-Посадов, М. М. Интернет-активность как обязанность ученого / М. М. ГорбуновПосадов // Информационные технологии и вычислительные системы. - 2007. - № 3. - С. 88-93.

4. Ефременко, Д. В. Концепция общества знания и ее оборотная сторона / Д. В. Ефременко // Концепция «общества знания» в современной социальной теории : сб. науч. тр. / ИНИОН РАН. Центр социал. науч.-информ. исслед. Отд. социологии и социал. психологии ; отв. ред. Д. В. Ефременко. M., 2010.- C. 66-97.

5. Иванова, Н. А. Понятия «габитус» и «хабитуализация» в контексте социологических теорий / Н. А. Иванова // Вестник Томского университета. Философия. Социология. Политология. - 2011. № 1 (13). - С. 115-129.

6. Кастельс, М. Информационная эпоха: экономика, общество и культура / М. Кастельс. - М. : Изд-во ГУВШЭ, 2000. -458 с.

7. Круткин, В. Л. Техники тела и движения человека / В. Л. Круткин // Журнал социологии и социальной антропологии. - 2014. - Т. 17, № 2. С. 167-179.

8. Миронов, Д. Ф. Информационный шум и образовательный процесс / Д. Ф. Миронов // Вестник СПбГУКИ. - 2015. - № 4. - С. 24-30.

9. Полудина, В. П. Информационный шум в Интернете как проблема потребления коммуникации / В. П. Полудина // Журнал социологии и социальной антропологии. - 2011. - Т. 14, № 5. C. 386-394.

10. Соколова, М. Е. Информационное пространство российской академической науки как интегрированная профессионально-интеллектуальная среда: перспективы формирования и управления / М. Е. Соколова // Концепция «общества знания» в современной социальной теории : сб. науч. тр. / ИНИОН РАН. Центр социал. науч.-информ. исслед. Отд. социологии и социал. психологии ; отв. ред. Д. В. Ефременко. - М., 2010. - С. 134-158.
11. Тоффлер, Э. Третья волна / Э. Тоффлер. М. : АСТ, 2004. - Электрон. текстовые дан. - Режим доступа: http://www.umk.virmk.ru/study/VMK/ LITERA/Toffler_Tretiya_volna.pdf(дата обращения: 02.11.2017). - Загл. с экрана.

12. Урри, Дж. Мобильности / Дж. Урри. - М. : Праксис, 2012. - 586 с.

13. Фуллер, С. В чем уникальность университетов? Обновление идеала в эпоху предпринимательства / С. Фуллер. - Электрон. текстовые дан. - Режим доступа: http://ecsocman.hse.ru/data/2010/12/24/ 1214866120/Fuler.pdf(дата обращения: 12.10.2017). Загл. с экрана.

14. Lash, S. Critique of Information / S. Lash. London : Sage Publications, 2002. -234 p.

\section{REFERENCES}

1. Abramov R.N., Kozhanov A.A. Kontseptualizatsiya fenomena Popular Science: modeli vzaimodeystviya nauki, obshchestva i media [Conceptualization of the Popular Science Phenomenon: Models of Interaction of Science, Society and Media]. Sotsiologiya nauki i tekhnologiy, 2015, vol. 6, no. 2, pp. 45-59.

2. Vaganov A.G. Uchenye i zhurnalisty: problemy kommunikatsii [Scientists and Journalists: Communication Problems]. Nauka. Innovatsii. Obrazovanie, 2016, no. 2, pp. 48-60.

3. Gorbunov-Posadov M.M. Internet-aktivnost kak obyazannost uchenogo [Internet Activity as a Scientist's Responsibility]. Informatsionnye tekhnologii i vychislitelnye sistemy, 2007, no. 3, pp. 88-93.

4. Efremenko D.V. Kontseptsiya obshchestva znaniya i ee oborotnaya storona [The Conception of the Knowledge Society and Its Flip Side]. Efremenko D.V., ed. Kontseptsiya "obshchestva znaniya» v sovremennoy sotsialnoy teorii: sb. nauch. tr. [The Conception of the Knowledge Society in Modern Social Theory]. Moscow, 2010, pp. 66-97.

5. Ivanova N.A. Ponyatiya «gabitus» i «khabitualizatsiya» v kontekste sotsiologicheskikh teoriy [The Concepts of "Habitus" and "Habitualization" in the Context of Sociological Theories]. Vestnik Tomskogo universiteta. Filosofiya. Sotsiologiya. Politologiya, 2011, no. 1 (13), pp. 115-129.

6. Kastels M. Informatsionnaya epokha: ekonomika, obshchestvo i kultura [The Information Age: Economy, Society and Culture]. Moscow, GUVShE Publ., 2000. 458 p.

7. Krutkin V.L. Tekhniki tela i dvizheniya cheloveka [Techniques of Human Body and Movement]. Zhurnal sotsiologii i sotsialnoy antropologii, 2014, vol. XVII, no. 2, pp. 167-179. 


\section{ФИЛОСОФИЯ}

8. Mironov D.F. Informatsionnyy shum i obrazovatelnyy protsess [Information Noise and the Educational Process]. Vestnik SPbGUKI, 2015, no. 4, pp. 24-30.

9. Poludina V.P. Informatsionnyy shum v internete kak problema potrebleniya kommunikatsii [Information Noise on the Internet as a Problem of Communication Consumption]. Zhurnal sotsiologii i sotsialnoy antropologii, 2011, vol. XIV, no. 5, pp. 386-394.

10. Sokolova M.E. Informatsionnoe prostranstvo rossiyskoy akademicheskoy nauki kak integrirovannaya professionalno-intellektualnaya sreda: perspektivy formirovaniya i upravleniya [Information Space of the Russian Academic Science as an Integrated Professional and Intellectual Environment: Prospects of Formation and Management]. Efremenko D.V., ed. Kontseptsiya «obshchestva znaniya» v sovremennoy sotsialnoy teorii: sb. nauch. tr. [The Conception of the Knowledge Society in Modern Social Theory]. Moscow, 2010, pp. 134-158.

11. Toffler E.H. Tretya volna [Third Wave]. Moscow, Izd-vo ACT, 2004. URL: http://www.umk. virmk.ru/study/VMK/LITERA/Toffler_Tretiya_ volna.pdf. (accessed November 2, 2017).

12. Urri J. Mobilnosti [Mobilities]. Moscow, Praksis Publ., 2012. 586 p.

13. Fuller S. V chem unikalnost universitetov? Obnovlenie ideala $v$ epokhu predprinimatelstva [What is the Uniqueness of Universities? Updating the Ideal in the Age of Entrepreneurship]. URL: http:/ /ecsocman.hse.ru/data/2010/12/24/1214866120/ Fuler.pdf. (accessed October 12, 2017).

14. Lash S. Critique of Information. London, Sage Publications, 2002.

\section{Information about the Authors}

Svetlana B. Tokareva, Doctor of Philosophical Sciences, Professor, Head of Department of Philosophy, Volgograd State University, Prosp. Universitetsky, 100, 400062 Volgograd, Russian Federation, tokareva@volsu.ru.

Tatyana S. Gorina, Candidate of Philosophical Sciences, Associate Professor, Department of Philosophy, Volgograd State University, Prosp. Universitetsky, 100, 400062 Volgograd, Russian Federation, tsgorina@gmail.com.

\section{Информация об авторах}

Светлана Борисовна Токарева, доктор философских наук, профессор, заведующая кафедрой философии, Волгоградский государственный университет, просп. Университетский, 100, 400062 г. Волгоград, Российская Федерация, svet-tok2008@yandex.ru, tokareva@volsu.ru.

Татьяна Сергеевна Горина, кандидат философских наук, доцент кафедры философии, Волгоградский государственный университет, просп. Университетский, 100, 400062 г. Волгоград, Российская Федерация, tsgorina@gmail.com. 